\title{
Estudio filosófico sobre la mirada estética en el diseño
}

\section{Resumen}

Este estudio ofrece un novedoso planteamiento teórico sobre la estética en el diseño. La investigación se concentra en las diversas ideas filosóficas próximas a la estética del diseño (la experiencia estética, las formas sensibles o espirituales, la adquisición científica, la consecución del ideal). El individualismo estético frente a la colaboración (entre diseñador y público), la conversión de la imaginación en experiencia sensible, el salto del diseño desde la contemplación a la acción, la expresión de las emociones individuales o la exasperación del aburrimiento del consumismo son aspectos vislumbrados por una teoría estética del diseño. En nuestra deliberación filosófica, los resultados no arrojan una exposición de verdades eternas sobre la naturaleza del diseño. El artículo tampoco es un mero ejercicio intelectual. También ofrece explicaciones a problemas de hoy que el diseñador encuentra en su práctica creadora. La configuración de una estética del diseño requiere de un proyecto interdisciplinar que conciencie sobre las carencias de las teorías estéticas del arte (a falta en el pasado de una estética del diseño debido a su desconsideración como género artístico y, en otros casos, a su depreciación como arte menor) junto con las tesis sociales sobre el mundo contemporáneo y la perspectiva crítica de los estudios de la cultura.
Fernando R. Contreras

Doctor en Filosofía. Doctor en

Ciencias de la Información

Profesor Titular Facultad de

Comunicación Universidad de Sevilla

Sevilla, España

Correo electrónico: fmedina@us.es (D) orcid.org/0000-0003-1105-5800 Google Scholar

Recibido: Enero 23 de 2017 Aprobado: Octubre 10 de 2018

Palabras clave:

Arte, cultura, diseño, estética, filosofía. 


\section{Philosophical study on the aesthetic look in design}

\begin{abstract}
This study offers a novel theoretical approach on aesthetics in design. The research focuses on various philosophical ideas close to the aesthetics of design (the aesthetic experience, the sensitive or spiritual forms, the scientific acquisition, the achievement of the ideal). Esthetic individualism versus collaboration (between designer and audience), the conversion of the imagination into sensible experience, the leap of design from contemplation to action, the expression of individual emotions or the exasperation of the boredom of consumerism are aspects envisaged by an aesthetic theory of design. In our philosophical deliberation, the results do not yield an exposition of eternal truths about the nature of design. The article is not a mere intellectual exercise either. It also offers explanations to today's problems that the designer finds in his creative practice. The configuration of an aesthetics of design requires an interdisciplinary project that acknowledges the shortcomings of the aesthetic theories of art (in the absence of a design aesthetic in the past due to its disregard as an artistic genre and in other cases, its depreciation as minor art) together with the social theses on the contemporary world and the critical perspective of the studies of culture.
\end{abstract}

Key words:

Art, Culture, Design, Aesthetics, Philosophy. 


\section{Introducción: entre el arte del diseño y la estética del diseño}

La naturaleza funcional del objeto de diseño ha sido el principal obstáculo para que fuese apreciado su valor artístico, aunque el objeto hubiese sido creado por un gran maestro. Recordemos los magníficos dibujos de las máquinas del artista renacentista Leonardo da Vinci. El origen de esta devaluación estética proviene de la tradición filosófica clásica, que Kant (2004) revitalizó insistiendo en la inutilidad de la belleza de la obra de arte frente a la vulgaridad utilitaria de los objetos cotidianos (o de aquellos objetos creados por el diseño). Este impedimento fue perdiendo influencia a medida que la posmodernidad imponía su régimen relativista de la cultura. Los objetos de diseño se incorporaron a los museos y se exhibieron en las galerías de arte. Fueron adquiridos por las colecciones privadas y, en resumen, conquistaron los espacios reservados para la obra de arte. Sin embargo el análisis del objeto de diseño aún está lejos de la dedicación profunda que se destinó al estudio de la obra de arte desde las tradicionales disciplinas tales como la historia del arte, la teoría del arte o la estética.

A mi juicio, el desaire al diseño no terminó hasta la fundación por Walter Gropius de la Staatliche Bauhaus en 1919. Quizás es la referencia más destacable que se pueda citar en la historia del diseño, pero también hubo otros fenómenos culturales que promovieron su evolución. Las tendencias del consumo, los estilos de vida, la cultura de masas, las doctrinas neopolíticas de la posmodernidad, el culto exacerbado a las ciencias sociales en las prácticas profesionales, la comunicación y una reciente epistemología de lo visual complican aún más la reflexión sobre el diseño y su relación con las artes en este comienzo de siglo.

Entre el arte, el consumo y sus tendencias surgió una conexión que se conoció por Warenästhetik (estética de los artículos de consumo). El autor del término 
fue el sociólogo Wolfgang Fritz Haug (1987, 1989), quien insistió en la importancia de la estética en la fabricación de los objetos. Las cosas reciben un tratamiento estético determinado que seduce a los sentidos y sugestiona al hombre desde lo sensual-gustativo. Según Thomas (2001), con la Warenästhetik se consigue alcanzar otra meta:

esta seducción estética puede ser manipulada de tal manera que despierte un deseo posesivo superior al que merece el valor económico y de consumo propios de la mercancía, al concentrarse el afán adquisitivo exclusivamente en el efecto sensorial a causa de la publicidad y de la influencia del diseño. (p. 201)

El mismo Karin Thomas introduce otro antecedente histórico que vincula al arte, a la estética y al consumo. En 1907 se funda en Múnich la Deutsche Werkbund, una asociación de prestigiosos diseñadores que trabajan el modelado industrial utilizando prototipos prácticos. Estos creadores tuvieron una gran influencia durante la segunda etapa más funcionalista de la Bauhaus dirigida por Moholy-Nagy.

Para el posterior desarrollo del diseño, el descubrimiento del consumo como una nueva racionalidad estética es trascendental. El paradigma posmoderno de lo visual, más lejos del dogmatismo de la historia del arte, amplía sus territorios sin explorar en el diseño y en los medios de comunicación. La transformación de las condiciones sociales en el mercado global enardece el conflicto humano entre la utopía de la igualdad de bienes y la ideología capitalista presente en la subjetividad del diseño en la cultura occidental. En este contexto, Gillo Dorfles plantea el nacimiento de nuevas formas expresivas que establecen puentes entre la cultura de las élites sociales y la cultura de masas. Dorfles señala al cine, la televisión, el grafismo publicitario, el diseño industrial, entre otros, como elementos constitutivos de la auténtica realidad artística de nuestro tiempo. Las nuevas cuestiones que pregunta, son: “¿dónde comienza, entonces, y dónde acaba el campo que hay que atribuir al arte? ¿Dónde se sitúan sus confines y sus límites?" (Dorfles, 1974, p. 20). 
El arte del diseño aprenderá a combinar las tendencias estéticas y la producción industrial en el ámbito del arte y de la comunicación. Siempre en la disyuntiva de lo novedoso, la innovación artística será el valor taxativo del diseño. Groys (2005), lo define así: "la innovación no consiste en que comparezca algo que estaba escondido, sino en transmutar el valor de lo visto y conocido desde siempre [...]. La transmutación de los valores es la forma general de la innovación" (p. 19). La vigencia de lo valioso pierde valor que recupera solo mediante la transmutación de aquello que antes se estimaba sin valor dando origen a las tendencias del consumo puesto que, como sostiene Groys (2005), son procesos económicos.

Finalmente se destaca que la orientación de este estudio es construir miradas de tensión teórica desde un pasado filosófico sin conexión a las formas modernas del capitalismo que, además, han influido tanto sobre la disciplina del diseño y su fuerte carácter contemporáneo. Tampoco es un objetivo del estudio establecer los parámetros definitorios de las diferentes estéticas del diseño en nuestros días.

\section{Metodología: visiones, revisiones}

En este estudio, la dimensión estética del diseño nace de la impresión inmediata ante cosas puntuales pertenecientes a la "cultura visual". El diseño surge de la corriente caótica de la vida cotidiana; concibiéndose como un todo autocontenido y autónomo, coherente y con una delimitación cierta. El respeto a una metodología filosófica en este estudio queda expresado tácitamente en estas palabras de Simmel (2013): "el arte en cuanto arte sólo nace de la dinámica artística. No quiere esto decir que el arte empiece a partir de la obra acabada. El arte proviene de la vida..." (p. 15).

Sin alcanzar la hierática altura e inconmovible soberanía de la ciencia, el estudio filosófico estético también contiene elementos entrelazados con la 
totalidad empírica de la vida. Por su parte la estética no tiene que ser normativa como la historia ni tampoco valorativa, definitoria, axiológica como lo es la crítica. Para algunos (Huisman, 2002), la estética es la ciencia del arte. En el estudio del diseño desde esta perspectiva, como en la ciencia, el conocimiento nuevo también exige el dictado de sus convenientes normas y la creación de sus propios contenidos; es decir el progresar en torno a la entereza de sus respectivas ideas. Para ello hemos seleccionado determinados autores que con sus distintas aportaciones permiten una aproximación a la conceptualización de la estética del diseño (Aicher, 1994; Alpers, 2001; Bal, 2016; Baudrillard, 1999; Berger, 2006; Collingwood, 1960; Croce, 1945; Dorfles, 1974; Flusser, 2002; Fried, 2000; Fritz Haug, 1987; Greenberg, 2002; Groys, 2016; Hadjinicolaou, 1975; Harman, 2015; Heidegger, 2012; Lipovetsky, 2004; Marx, 2008; Rosler, 2017; Wollen, 2006; Wollheim, 1972). Algunos autores han tratado directamente la cuestión del arte. En cambio, otros contribuyen desde las aportaciones de los estudios de la cultura con sus críticas adaptadas al conocimiento de la estética del diseño (Calvera, 2007; Heller, 2008; Infante del Rosal, 2018; Julier, 2010; Leborg, 2013; Meggs, 2009; Morris, 2005; Munari, 2005; Sparke, 2010). Básicamente los estudios sobre la cultura han aportado la tesis de la construcción social de lo visual a este estudio (Contreras, 2017).

\section{Mirar la estética en el diseño desde una perspectiva moderna}

Desde la obra de Croce (1945) podríamos hacer un primer diagnóstico que discurriría sobre lo que dijo en su breviario estético. Para Croce, la definición de arte implica una serie de negaciones. El diseño, como el arte, no es un fenómeno físico. Todo fenómeno físico es irreal y el arte es real. Según Croce, los fenómenos físicos tienen semblanza de mentira. Salvo para los filósofos materialistas, estos fenómenos son una demostración de la irrealidad del mundo. La ciencia es testimonio de principios estéticos que proceden continuamente de la experiencia. El arte es real cuando ignoramos la significación venida de su construcción física: 
"ya que cuando nos proponemos penetrar su naturaleza y el modo de obrar de ella, de nada nos vale construirla físicamente" (Croce, 1945, p. 20).

Otra controvertida negación de Croce es la definición de arte como intuición. Su razonamiento establece que si el arte es intuición y la intuición es valorada en el sentido original de la contemplación, el arte puede ser un acto utilitario. Este acto utilitario concretamente produce placer y evita el sufrimiento humano. No obstante, la negación del acto utilitario anularía el carácter hedonista de la obra de arte. El acompañamiento placentero es común en toda actividad estética o cualquier otra actividad espiritual; y no es contraria a la idea de que el arte no pueda ser agradable. Llegados a este punto, Croce plantea otra negación: si el arte es intuición no por ello es un acto moral que nos acerca a lo agradable, a lo utilitario o al dolor.

El arte no se independiza de la teoría moralista; al contrario, permanece unida a su naturaleza estética hasta nuestros días. Croce observa que las doctrinas morales adheridas al arte desacreditan, por lo que supone la imposición de tendencias concretas.

Pero como bien admite Croce, el arte no puede hacerlo todo. Al arte se le han atribuido responsabilidades más propias de la historia o de la filosofía. Por ello se ha buscado hallar tribunales morales en sus objetos o en sus fórmulas de distinción entre lo verdadero y lo falso. En la idiosincrasia de la imagen se ha querido ver una referencia a lo universal, así como la figura de Dios ecuménico. De esta manera el arte puede ser reconocido en cualquier lugar del mundo. Este idealismo del arte también aparece en el diseño. Frente a esta nobleza estética, el diseñador ultima el diseño cuando se convierte en crítico de sí mismo; y también cuando fenece el trabajo del diseñador con el público, que ya no contempla la estética del diseño sino que mira la vida a través de ella (lo que era propio de la historia o de la filosofía). 
Para terminar con la reflexión de Croce analizaremos los límites del espíritu, la crítica y la unidad del arte. Así pues, el espíritu del arte se iguala a la concepción de la naturaleza que aúna los objetos entre objetos y las cosas entre las cosas. De este modo si se agota la física del arte o, lo que es lo mismo, las clasificaciones naturales de las gramáticas, poéticas, retóricas y preceptivas de toda condición, precisa Croce, igualmente se agotan las formas extrínsecas y verbales o las mismas obligaciones éticas del arte. La apertura de Croce hacia nuevos conceptos desprendidos del arte, ofrece cabida al diseño. Sus obras nacen sin ligazón al pasado, sin doctrina, sin un orden sistemático, pero dispuestos con la coherencia necesaria para discernir lo bello de lo no bello, lo poético de lo no poético, lo auténtico y verdadero de lo falso, lo ético de lo amoral. Y ello solo es posible a partir de la satisfacción de pensar en aquello en lo que no piensan los hombres del presente: "Ilegará un tiempo para el cual la edad en que vivimos, que hoy nos parece tan luminosa, estará representada con sus límites porque la habrá sobrepujado otra edad" (Croce, 1945, p. 108). Para Croce no existen los períodos históricos del arte, los movimientos estilísticos, los géneros o cualquier división que tradicionalmente ha establecido la historia o la crítica. El hueco abierto en la tradición materialista del arte considera un ideal a la obra artística. Al no ser necesaria la exteriorización física, elevamos el diseño al mismo nivel que la obra de arte. Visto desde esta perspectiva, ambas creaciones son arte desde su concepción en la mente (proyección) del artista o el diseñador sin que forzosamente sea materializado en un objeto (diseño, pintura, escultura, fotografía, literatura entre otros), sin la necesidad incluso de que el público llegue a conocerlo.

\section{El razonamiento epistémico en la estética del diseño}

Wollheim (1972) contribuye al conocimiento del diseño con la búsqueda de lo distintivamente estético, prescindiendo de los elementos superficiales. Para ello nos propone entrar en la mente organizadora que realiza el artefacto 
o la fabricación de una forma artística. Su razonamiento sobre lo que es característico del artesano respecto al trabajo del artista es distintivo de la consideración de una estética del diseño y de su valor artístico. En su estudio introductorio a la estética, Wollheim tiene preferencia por los principios del arte enunciados por Collingwood (1960) que por los criterios de Croce (1945) para esta cuestión. Enumera tres características diferenciadoras entre el arte y la artesanía que sirven para comprender la distancia epistémica entre el arte y el diseño: (i) el diseño podría concretarse a partir de los medios empleados para conseguir que la forma artística de la creación cumpla con un fin; (ii) el diseño incluye dos momentos en su proceso creativo: la planificación y la ejecución. La planificación gravita alrededor de la suposición del resultado anhelado y en el estudio de cómo desarrollarlo mejor. La ejecución sería la realización de lo planificado; (iii) el diseño supone trabajar con un material que transforma tras el proceso creador en el objeto deseado y el resultado siempre es algo disparejo a su materialidad (Wollheim, 1972).

El arte, continuando con la reflexión de Wollheim (1972), no es cierto totalmente que no posea un fin: "ahora bien, ¿por qué dirá alguien, el fin del Arte no puede ser, por ejemplo, la simple producción de un objeto expresivo?" (p. 63). Esta pregunta tiene un razonamiento epistémico espinoso, ya que podría plantear que los medios y el fin se conciben separadamente o supondría una asimilación del arte a la artesanía (o al diseño). El artista no es capaz de calcular con todo lujo de detalles lo que realmente quiere crear. Detrás de la distinción tradicional entre arte y diseño están siempre los postulados (o prejuicios) de una teoría ideal. Esta teoría estética admite una serie de certezas empíricas, pero también inherentes a la experiencia intuitiva del artista. La primera de estas certezas es la desconexión entre el artista y el público cuando la obra de arte se reduce a algo interno o mental del artista. En este caso, solo el artista comprendería verdaderamente lo que ha producido. Por otro lado, la teoría ideal desdeña la significación del medium. Wollheim 
(1972) devalúa la valía del medium en esta cita: "un poema o un aria podrían existir en la cabeza del artista antes de que fueran escritos..." (p. 65). En las artes musicales o en la literatura, el arte puede realizarse sin necesidad de exteriorizarse contingentemente sobre una forma artística. Podría ser objeto de otras experiencias diferentes a la materialidad del diseño o, dicho de otro modo, el diseño no es posible si la experiencia estética no es interna o mental. En este sentido el arte y el diseño coinciden en la misma condición.

Lo considera Collingwood (2016), y lo admite Wollheim, que la experiencia estética de la obra de arte (y, en nuestro caso, del diseño) es a la vez creación y aprehensión. La esencia del arte es que todo ha de imaginarse y que, por esto, no tiene sentido interrogarse si la obra posee o no una existencia autónoma de nuestro prendimiento de la misma.

Desde esta aprehensión de la existencia externa del objeto de diseño también asoma otra dificultad contemplada en el arte, ¿qué percibimos directamente en la obra? La teoría tradicional del arte establece que son las propiedades de una pintura, de una escultura o de un poema. A su vez, ello lleva a otra pregunta, ¿qué objetos reúnen las características idóneas para su consideración como obra de arte? Este camino ha conducido al arte hacia aquellas tesis que tratan la visión. Cada sentido humano obedece a unas cualidades que hacen a los objetos idóneos. Por ejemplo, la vista a los colores, los tonos o las texturas. De modo similar, sucede en el diseño. Podría considerarse que los elementos artísticos más inmediatos en la percepción del diseño son los modos visuales de representación que potencian las sensaciones sensoriales en el público. También, en este sentido, decimos que "diseñamos sensaciones".

Cuando trabajamos con sensaciones, el diseño sugiere propiedades específicas a los objetos en base a lo creado. Esas propiedades remiten a otras experiencias estéticas y al modo en que las describimos. El diseño se basa, entonces, en 
otras teorías a priori sobre aquello que conocemos directamente o sobre el significado de lo que sentimos. El diseño, como Wollheim afirma para el arte, adquiere una significación emotiva resultado de la resonancia natural. Esta reverberación es causada tanto por la sensación exterior de lo diseñado como por la incorporación de elementos internos invocadores de emociones en contextos diferentes.

\section{Estética textual y estética visual: hacia una fenomenología del diseño}

Para Berger (2006) es prioritaria la relación entre el significado visual y el verbal. Son las palabras las que sugieren lo que vemos. Esta idea tiene sus detractores. Boehm (2011) sostiene que no existe justificación filosófica para aceptar que lo lingüístico domina a lo visual como una forma más poderosa de significación (Moxey, 2015). Berger explicaba la comprensión del mundo a través de la fotografía. Las imágenes fotográficas mostraban las apariencias del mundo creadas con los medios de la nueva esencialidad visual. Se anticipaba en su descripción del mundo visible a la noción de simulacros que ofrecería más tarde Baudrillard (1984), ya en plena posmodernidad. La influencia de la tradición fenoménica europea fortaleció el método de análisis visual de Berger. Para él, ver consistió en aprender de la misma obra sin considerar su naturaleza, su ideología de clase o sencillamente sus limitaciones históricas. El estudio narrativo que hace Berger de las imágenes ofrece una insólita perspectiva a la comprensión estética del diseño cuando se contempla que hacen sus obras. La implicación de una estética del texto en el relato de lo visual muestra una fenomenología diferente del arte. En la reflexión de Berger, lo textual del objeto visual se extiende hasta la comprensión de la realidad circundante. Otras narraciones germinan en la esencia visual del diseño. Aparece la acción destructora del capitalismo sobre la historia. El capitalismo, a diferencia del marxismo, solo tiene interés en la ruptura con el pasado con el objetivo final de priorizar las cosas que todavía no han tenido lugar (o no han sido creadas). 
Para Berger es importante la obra que hace el arte, independientemente de sus medios de expresión o las circunstancias que envuelven a esa obra. En su reflexión, la obra artística no depende de la tradición ni de las costumbres ni del repertorio de ideas heredadas del pasado. Para él, el significado proviene de la evolución de los espacios de la estética. En estos espacios aparecen las aspiraciones comunes a los espectadores y a los objetos. Si se engarzan estos anhelos con el trabajo de creación de los artistas, entonces surgirá el significado de la obra que siempre acusa el tiempo presente.

La mirada fenoménica de Berger proporciona alineaciones del sentido narrativo de la vida; la obra visual adquiere la función del relato literario. Desde esta perspectiva, los objetos artísticos consisten en aproximaciones a la experiencia visual que nunca considera completamente propia dado que las experiencias cotidianas siempre le han precedido. En cualquier caso, la experiencia estética es escrutinio (cercanía) y la facultad de conectar (distancia). El arte explora la artificialidad que le permita construir modelos globales sobre la verdad de las cosas que no se halla en la experiencia de la realidad. Así, la mirada de Berger se aproxima a la concepción de diseño debido a que la tarea del diseñador o del artista no es representar o imitar existencias dadas ("resumir la experiencia"). El poder del artista, como del diseñador, reside en la artificialidad creada: "la obra de arte ya no representa la naturaleza, sino que es él, el espectador, quien la representa" (Berger, 2006, p. 195). De ahí que el arte reconstruya hechos reales de una época basándose en el testimonio de testigos presenciales como en la obra de Francisco Goya: "El fusilamiento del 3 de mayo" (1813-1814). Lo que acontece en el arte es una superación de la naturaleza como campo de estudio. La cultura renacentista imitaba la naturaleza, pero el modelo de arte que va naciendo en el Romanticismo y alcanza el diseño en el siglo XX es distinto.

Si partimos de Berger en nuestro razonamiento, el arte se puede usar como un método diagramático que explica las variables constantes de la vida; a diferencia 
de la visión del pasado (historia) que no quiso romper la continuidad de los tiempos. El arte fragmenta el espacio lleno o vacío de significaciones entre el espectador y su objeto artístico descubriendo sus interconexiones (de sentido o de verdad, de ethos o de orden; relacionado esto último con el pulchrum, de lo universal o de lo particular). Frente a esta discontinuidad del espacio, el diseño ofrecerá la estructura o el diseño modular que conforma la vida digna. La modularidad corresponde a las relaciones entre la creación y el hombre a partir de sus diversas funcionalidades. El objeto artístico presentará una nueva visión científica de la naturaleza y de la realidad humana. El 'arte' del diseño se constituirá en un laboratorio moderno en el que se distingue las obras sin una voluntad de alcanzar significados transcendentales. Más bien, será un recinto en el que surge una concepción científica del mundo que entrelaza ciertas historias naturales y sociales. Un laboratorio donde la acción estética de los nuevos medios de expresión y comunicación orienta la mirada hacia las totalidades. Berger sitúa esta visión del arte en el nacimiento del cubismo. El mismo carácter de una sagacidad diagramática, totalizadora, científica, surge en las vanguardias artísticas. La reducción de las formas figurativas de la naturaleza en otras formas geométricas (cubos, esferas, conos, pirámides) supone un cambio hacia otras estructuras estéticas. El mismo proyecto pedagógico de la Bauhaus responde flexiblemente a las contingencias de la industria (el cartelismo, el anuncio, el diseño tipográfico o el diseño industrial) en su programa formal y conceptual.

\section{La orientación cultural de la estética en el diseño}

La teoría de la cultura en el diseño pone el énfasis en la recepción. El aporte de Bal al arte desde los estudios de la cultura visual completa el planteamiento unilineal de la historia del arte. Los estudios sobre la cultura visual muestran la obra de arte como un objeto activo que media con el contexto social. Este aspecto escapaba de la misión de la historia del arte, ofuscada en la indagación 
de las fuerzas temporales que dan origen a formas determinadas de arte. Los estudios de la cultura visual, a diferencia de la tradición histórica, centran al espectador en el núcleo del estudio de la obra artística. En esto beneficia al conocimiento del diseño, ya que su ocupación epistémica atiende a otras cuestiones diferentes de la historia del arte: la polisemia de los signos visuales; la construcción social del sentido de estos signos y su poder efectivo sobre los espectadores. En este contexto, el diseño puede interpretarse como una encarnación estética si entendemos el hallazgo de su significado como un acontecimiento delimitado por el espacio y el tiempo. Es decir que el diseño solo adquiere significado para el hombre cuando su naturaleza objetual establece un encuentro con el valor estético en el presente. Bal reconoce este encuentro en la obra de arte, lo explora e identifica su marco social integrado en la misma naturaleza de la obra de arte, operando en ella.

Desde la variabilidad cultural, el diseño construye esquemas simbólicos a partir de su comprensión semiótica. Las obras del diseño consiguen una forma específica de pertenencia diferente al resto de las obras artísticas. El diseño se arroga el monopolio cultural en los espacios públicos. A partir del siglo XX, el diseño visual persiste por su acción comunicativa (el diseño de marca, el desarrollo del diseño comercial, el diseño editorial o el diseño tipográfico). La comunicación enriquece el acervo cultural del espectador necesario para la traducción o interpretación estética del diseño (o la obra de arte). Aunque en la configuración del contenido y del esquema simbólico es ineludible la interpretación individual, el entorno social del diseño le confiere a la obra un residuo semántico al que es difícil acceder. Betts (2017) destaca también el valor de la mediación cultural:

sobre esta deducción, es claro, entonces, que el diseñador es uno de estos agentes que posee la virtud de erigir asociaciones semiológicas en la acción de proyectar usando como receptáculo los criterios de función y forma de los objetos bajo estrategias (retórica) que persiguen instituirlos y difundirlos. (p. 172-173) 
La mediación cultural en el diseño consiste en una negociación en la que perfilamos un lugar en el mundo social donde se producen las tensiones de la vida cotidiana. Tanto el arte como el diseño poseen la capacidad de crear un espacio al otro. Para Aicher (1994) este espacio es la técnica: "la relación entre arte y técnica es irreversible. La técnica tiene una belleza propia, técnica, pero no vale a la inversa: que el arte tenga una dimensión técnica" (p. 23). De hecho, el arte dependía de su técnica hasta el Romanticismo porque así se adiestraba al artista en la repetición de los cánones artísticos y bajo la influencia de los mismos avances de la ciencia (p. ej., los descubrimientos de la óptica y su consecuencia sobre el impresionismo). Esta costumbre finalizará con la invención del ready-made del artista Marcel Duchamp (Blainville-Crevon, 1887, Neuilly-sur-Seine, 1968). El arte se independiza de su materialidad y, por tanto, de la necesidad de la técnica en su producción. La presencia de la técnica continuará vigente en su función comunicativa, social, política y reivindicativa. Es precisamente el espacio de contacto que el arte o el diseño crean lo relevante. Por ello el estudio de la cultura visual no es tanto la observación de objetos seleccionados (aquellos objetos que tradicionalmente señala la historia del arte) sino aquello que generan. Bal (2016) profundiza más en esta cuestión, al afirmar que: "describir históricamente es el ejercicio del poder a través de la visión y de la creencia en la primacía de la visión. Este punto de vista reconoce el carácter indispensable de la filosofía en el análisis visual" (p. 34). En el acto perceptible del diseño (como en la obra de arte) nunca falta la dialéctica entre el poder y el conocimiento; y con ello, tampoco se limita exclusivamente a lo cognitivo; el poder opera precisamente por medio de esa relación. Esto mismo fue formulado a su modo por Baudrillard (1999) cuando explica el funcionamiento del sistema de los objetos; y antes que él, Marx (2008) cuando introduce el concepto de plusvalía de la mercancía. Los objetos adquieren un poder haciendo visibles esos aspectos que de otro modo permanecerían invisibles. La visibilidad de los objetos del diseño está sujeta al régimen de verdad que supone la representación de los discursos racionales aceptados. 


\section{El régimen estético de los objetos visuales: forma, materia y espíritu}

Las creaciones del diseño obedecen a sensibilidades pluralistas que buscan el arte en otras manifestaciones humanas (culturales) concebidas como no primitivas. Podría pensarse que el diseño ha sido considerado un estándar artístico discriminado por una conspiración histórica que debe contemplarse con cierta suspicacia. Milton Glaser (2017) sostiene que es la respuesta a la falta de un propósito espiritual en el diseño, aunque también opina que: "a lo largo de la historia, el arte ha tenido una función y ha obedecido, casi sin excepción, a una directriz" (p. 31). Para Glaser, el arte es un asunto que concierne la transformación metafísica del hombre. Lo que importa no es la categoría o el medio sino la experiencia que provoca sobre el hombre: "el arte que experimentamos nos afecta y nos mueve, de la manera más profunda e inconsciente, a percibir nuestra propia realidad" (p. 73).

El régimen estético de los objetos visuales comienza por la oposición originaria "materia-forma". Esta tesis fue desarrollada por Flusser (2002), al afirmar que el diseñador ya no ve materia sino la forma sobre la materia.

El régimen de los objetos reúne la filosofía clásica idealista y la filosofía barroca materialista. Flusser llega a esta conclusión a partir de la oposición entre materia-forma. Las formas son modelos de fenómenos, no son ficciones ni son ideas platónicas. Las formas transforman la materia en ciencia teórica cuando su inmaterialidad no es verdadera ni falsa, pero si 'formal'. Según da a entender Flusser (2002) en el diseño, como en cualquier articulación cultural, la materia no se muestra (no posee apariencia) y solo surge a la visión del hombre cuando es "in-formada"; es decir que dotada de semántica empieza a parecer objeto (se vuelve fenoménica). La materia es mediadora en el diseño para que las formas aparezcan. Esta tesis sustenta que la estética de los objetos 
es de naturaleza informacional y alcanzará un extremo más radical (Flusser, 2017) en el análisis de las imágenes técnicas, concretamente con las imágenes generadas por las máquinas. De modo que la existencia de los objetos reside cada vez más en los formalismos creados por las máquinas (fotográficas, cinematográficas, ordenadores). Estos formalismos visuales dotan de diálogo a las redes digitales. Las sociedades modernas se caracterizan por una razón dialógica y no por los discursos como sucedía, por ejemplo, durante la Edad Media con el cristianismo. Nuestra sociedad repite con el diálogo visual introducido en la cultura moderna a partir de la Ilustración para describir la ciencia, el arte o la política. Para Flusser, la cultura de las redes telemáticas es una vuelta a la cultura eclesiástica (salvando las diferencias). Pues la cultura dialógica eclesiástica se basaba en la autoridad, mientras que la cultura dialógica de las redes digitales es automatizada por las máquinas y no admite autor ni autoridad ni autoritarismo. El diseño contemporáneo se desenvuelve en una cultura abierta para todos al diálogo creativo que procura el sentido a los objetos visuales.

\section{La experiencia estética del diseño}

El diseño debe ser entendido como Idealtypen, como una forma ideal, una forma pura que aspira a materializarse. La historia del diseño es la historia de la cultura occidental que rompe con prejuicios epistémicos nacidos en la cultura clásica. El origen de este conflicto epistémico-estético se encuentra en la imperfección que en el pasado supuso el saber de la realidad sensible (praxis) y la producción en el mundo del devenir (poíesis). Estos prejuicios continuaron entre el saber hacer (phrónesis) y el saber actuar (tekhné) más presente en la condición del diseño. Estos prejuicios comenzaron a desaparecer a partir de la relación entre el arte, la ciencia y la técnica durante el Renacimiento. Durante La Modernidad el conocimiento de la causa del fenómeno se transformó en el efecto del fenómeno dado que activa o no la causa productora del efecto- 
fenómeno. Por ello se interpretó al saber tal como poder hacer, poder modificar, transformar o producir. El diseño se enmarca en esta tradición moderna de la ciencia causal más próxima a la técnica (tekhné, ars). La técnica sigue excluida de la pureza de la ciencia, como el diseño de la pureza del arte durante La Modernidad. Ha derribado estas obcecaciones una visión más tecnocientífica del mundo en la posmodernidad.

Hoy en día, el propio discurso que el diseño ha hecho de sí mismo exhibe a los objetos visuales como referentes de la cultura de nuestro tiempo. Un discurso que se caracteriza por: (i) la autorreferencialidad en una cultura dominada por la producción masiva de objetos industriales e imágenes; (ii) los hombres se conciben a sí mismos como extraños en relación con un mundo contenido de objetos creados por el diseño. En este caso, los objetos de diseño configuran una cosmología propia. Los objetos acaban adquiriendo una materialidad significante para después conseguir un significado inherente desde la interpretación y finalmente su consideración como parte integral de la existencia de los humanos (Baudrillard, 1999); (iii) el diseño revela el conocimiento legítimo científico cuando con sus objetos describe los fenómenos de auto/des/ ocultamiento del mundo. Desde el concepto heideggeriano de 'Ser' (Dasein), el conocimiento desvelado puede ser sustancia que se presenta ante nosotros con sus significados inherentes sin necesidad de que una interpretación nos explique cómo puede transformarse en significado. Por esta vía asumimos que el diseño es un signo de la cultura con una estructura metafísica, la cual es al tiempo materia significante con un significado puramente espiritual; (iv) el diseño siempre es una acción, es decir, una práctica que hace presente cosas que están ausentes o todavía no existen y viceversa hace desaparecer otras cosas; ( v) en la cultura visual contemporánea, el diseño obedece a la pugna entre diferentes motivaciones individuales. La estética del diseño se enfrenta a diferentes cosmovisiones de un futuro vetusto. Además orienta indirectamente la conducta individual y el comportamiento colectivo en un futuro inmediato. 
La experiencia estética del diseño despierta sentimientos que no podemos encontrar en los mundos cotidianos. Es por ello que puede presagiar las necesidades y los deseos que habitan en lo íntimo de una cultura específica.

El diseño crea imágenes-signo que nunca son representantes vacíos de una reserva fija de epifenómenos intercambiables del mundo. Los objetos obedecen a un contenido específico con el que tropezamos a través de la percepción, pero también frente a ellos nos encontramos dispuestos hacia esa percepción.

La experiencia estética del diseño (o del arte) nos fascina porque siempre es algo que no nos pueden ofrecer los mundos cotidianos. Además, estos objetos tienen que ser culturalmente específicos. A nuestro juicio, el diseño da origen a formas de reacción y recepción que solo se experimentan a través de las transformaciones estéticas. "El ser-objeto no constituye el ser-obra de las obras" (Heidegger, 2012, p. 29). Por ello los objetos del diseño aparecen en una situación que los encuadra en el lugar y en el tiempo donde tienen que ocurrir. En esa posición, adquieren una autonomía estética que los distancia del orden cotidiano y así obtienen su independencia subjetiva: "ser obra significa levantar un mundo" (Heidegger, 2012, p. 319).

\section{Cuestiones finales de la estética del diseño en la posmodernidad}

Durante el Romanticismo, los artistas comprendieron que detrás de los temas cotidianos de una pintura se encerraba un interés por una verdad de orden general. Así lo enseña Alpers (2001) en su estudio de la obra de Rubens. En sus pinturas, observó una extensión circunstancial que se correspondía con otra dimensión supra-circunstancial tanto en la temática como en la resolución (política, ideológica). En la posmodernidad, la estabilidad racional conseguida en La Modernidad es interrumpida por una inestabilidad radical que también envuelve a la estética. Existe cierto miedo a la distorsión de las 
artes visuales provocada por la cultura de masas, el entretenimiento, el kitsch, el pastiche o la hibridación cultural. La misma salida de las artes visuales de su ensimismamiento moderno descubre la fragilidad que supone pensar solo en la pureza e integridad del arte y perder la consciencia de la condición necesaria para su existencia.

Es imposible negar que el Romanticismo renunciara a las cuestiones morales; concretamente a la misión moral de la pintura (por ejemplo, a los ojos de Diderot), en el contexto de su concepción dramática del arte. A finales del siglo XX, estas cuestiones se extendieron a la concepción política del arte. Flusser (2002) lo ilustra cuando señala al diseñador de las cámaras de gas de los campos de exterminio judío durante la Alemania nazi. Esta preocupación moral en el diseño ha alcanzado hasta los actuales códigos deontológicos del diseño publicitario. Del Romanticismo, el diseño ha heredado también la acción y la pasión y el culto a los objetos que en la pintura constituía el género de naturalezas muertas. El sentimentalismo, las emociones y el interés por captar el alma del espectador a través de sus ojos son también tareas del diseñador contemporáneo que el pintor romántico redescubrió:

primero, un cuadro tenía que atraer (attirer, appeler), después atrapar (arrêter) y finalmente extasiar (attacher) al espectador; es decir, un cuadro tiene que Ilamar la atención de alguien, Ilevarle a cierta perplejidad y retenerle, embelesado incapaz de moverse. (Fried, 2000, p. 115)

Estas lecciones del arte romántico tan obvias y comunes fueron reproducidas en el diseño publicitario y en el arte moderno. Con ello permitieron al espectador alejarse de una realidad desalentadora de la sociedad hacia un espacio estético, autocontenido, donde se eliminaron los enredos políticos o ideológicos. El diseño se aceptó como una actividad artística. La desaparición del tema en el arte evitó las referencias al mundo real, a la naturaleza, a la historia o al mundo subconsciente de los sueños o de la imaginación fantasiosa. El arte evitaba convertirse en un instrumento de la política o de las ideologías. Para críticos 
como Greenberg (2002), las sensaciones sensoriales ópticas eran la materia del arte. Esta visión tradicional contrasta con la fascinación por lo vernáculo urbano y los nuevos estilos de vida que surgen en las ciudades. La creatividad busca su impulso en los gustos populares y en las formas de entretenimiento de la gente común. De este modo el arte comienza a buscar un material original en la propia vida contemporánea y en sus creaciones populares (la publicidad, la fotografía, el cine, los rascacielos o la música jazz) (Wollen, 2006).

Con el advenimiento de la posmodernidad, la estética de lo efímero (Lipovetsky, 2004) y la estética de lo político (Groys, 2016) modificaron la dirección del diseño. La Modernidad pone en duda las jerarquías estéticas de los Anciens régimes, pero tras la Segunda Guerra Mundial el arte es invadido por un fuerte racionalismo y funcionalismo que resalta la misión del diseño. La cultura posmoderna adora los desarrollos tecnológicos, la producción industrial toyotista, el consumismo y la contracultura (un rechazo a los estilos de las corporaciones, de las reglas de la mayoría, de los códigos represivos y de la carrera militarista nuclear — cultura de la muerte-). El flujo cultural de lo bajo a lo elevado o de la periferia al centro se interpreta como el impulso social de la apropiación de la cultura y la innovación política. Según el esquema de Greenberg, el gusto era el factor clave de la sensibilidad de la sociedad. Con la aparición del gusto del consumidor se aniquila esta cosmovisión social de los artistas que suponía modificar las cuestiones culturales o transformar las políticas mediante el arte. La facultad kantiana del gusto para conquistar las audiencias no puede competir con el gusto de la cultura de masas que se convierte en expresión de pertenencia a una clase social y de estatus social. Bajo estas circunstancias, Rosler (2017) explica que las políticas de los estilos de vida y de las oscilaciones del gusto se convierten en políticas en sí e incluso en políticas de la vida cotidiana (Pérez-Henao, 2014) esparcidas mediante el fenómeno de la globalización a través de todo el mundo. El estilo de vida se convierte en el objeto central del marketing de los bienes de consumo. La 
imaginación creativa tampoco puede resistirse a la dominación del marketing que introduce su propia racionalidad. Las obras visuales se diseñan bajo el dictado de una política unificadora, globalizadora y determinante del modo de vida:

la gente hace alianzas basadas en el gusto, sobre todo a través de un tribalismo de la aparienciacomo-identidad. Los agrupamientos de los estilos mercantilizados no solo incluyen a las posesiones, sino también a las personas, a los logros y a los niños y tienden a ser costosos de adquirir y mantener. (Rosler, 2017, p. 201)

Las élites sociales ejercían su influencia sobre las oscilaciones del gusto en las sociedades pasadas. La historia del arte perpetúa todas esas variaciones de la ideología burguesa. En su estudio, Hadjinicolaou (1975) refiere la historia del poder de las imágenes de tema político como historia de la cultura e incluso como historia de las formas. Las investigaciones marxistas introdujeron las primeras cuestiones importantes de índole económica para pensar el diseño (la plusvalía de la creación artística), de índole política (la instrumentación propagandística de los objetos) o sencillamente literaria (el relato utilizado en la difusión popular del objeto de diseño). Estos aspectos han ocultado casi por completo otros esfuerzos por mostrar lo puramente estético del diseño durante décadas.

Cuando Hadjinicolaou afirma que la ideología de una imagen no es su 'Contenido', puntualiza una cuestión muy concreta: las imágenes sirven para albergar los contenidos de las ideologías. En estos términos, el diseño de una producción masiva en la industria es una ideología que se relaciona con otras ideologías como el capitalismo o el industrialismo.

La ideología de la imagen es una ideología propiamente "de imágenes" y no política o literaria, un tipo de ideología que no existe, como tal, más que en la forma de las dos dimensiones de la imagen, sin dejar de mantener relaciones específicas con los demás tipos de ideologías (literaria, política, filosófica, etc.). (Hadjinicolaou, 1975, p. 19) 
Cuando se sitúa al diseño bajo la óptica de la historia del arte, la tesis de Hadjinicolaou recuerda que estuvo dominada desde sus orígenes por la ideología burguesa. Tal como explica Hadjinicolaou la concepción de la historia del arte ha sido convencionalmente la historia de los artistas, la historia de las civilizaciones o la historia de las obras de arte. Todas ellas ocultan la relación profunda entre imagen e ideologías, entre arte e ideologías. La ideología burguesa ha sido, a mi juicio, la principal causa en La Modernidad para la discriminación del arte del diseño: "bajo la denominación arte se han reagrupado únicamente las obras consideradas mayores. Las obras consideradas como menores son ignoradas" (Hadjinicolaou, 1975, p. 21).

El capitalismo de la posmodernidad discriminó la estética en el diseño desde el aburguesamiento de los artistas. El arte quedó sometido a las exigencias que introduce el mercado de bienes. Como piensa Rosler (2017), todos los productos culturales sufren la fuerza apisonadora de la información que cruza el arte y el diseño con el entretenimiento, la ciencia, la tecnología y la literatura.

\section{Conclusiones}

De lo expresado podemos concluir en los siguientes puntos: (i) el estudio de la estética del diseño implica no ver solamente resultados y si recordar la importancia de los procesos. En los procesos aparecieron las relevantes razones comunes a la ya autoafirmación doctrinal del arte frente al diseño. Es como si la sublimación del arte fuese el único valor de uso teórico para la constitución de un arte superior sobre los resultados inferiores del diseño. La estética del diseño aparece exactamente ahí donde encontramos la reconciliación dialéctica, la pacificación de los conflictos teóricos o la unidad conceptual entre el arte y el diseño; (ii) la estética del diseño permite examinar de nuevo esas convenciones sociales surgidas de las opciones filosóficas como son el 'arte', el 'espíritu', el 'ser', la 'existencia' o la 'cultura'. La estética en el diseño nos conecta con 
la auténtica realidad tan alejada de lo real como de lo ideal. El mundo de la imaginación creativa es un mundo desordenado, dislocado, ya que de otro modo no habría arte ni cultura. Renunciar a las idealizaciones del arte permite ver en el diseño objetos de un extraordinario esplendor. La estética además muestra lo común que poseen una catedral, un cartel publicitario, un cómic y un hermoso adagio. El objeto del diseño es una cosa mental que pertenece a la imaginación, a la intuición y al sentimiento. Y aunque todo lo que se refiere a la estética es dudoso, a través de la misión del diseño el arte se relaciona con la ciencia y es susceptible de un tratamiento filosófico; (iii) en la posmodernidad, la estética y la moral se basan en la acción de la técnica y en la ciencia. Hoy en día, a la estética del diseño solo le quedan dos caminos posibles: consumirse en el pathos o transformarse en otra ciencia puesta al servicio de la producción industrial y el capitalismo.

Apenas se habla en el pasado de la estética del diseño en la filosofía del arte, aunque en su discurso ya se anuncia algunos postulados que repercutirán en los posteriores teóricos del diseño. Hemos presentado varias consideraciones importantes. Casi todas estas teorías han apreciado que la belleza no tiene que ver con la razón sino con la pasión que nos golpea de manera inmediata y que se adelanta al juicio racional. Y también que lo bello no es una categoría exclusiva de la estética. La estética en el diseño comienza con la emergencia de otras categorías artísticas: la misma funcionalidad política en la lucha social por la liberación del gusto o la validez de la creación artística sometida al cambio histórico, independientemente de la forma que transforma la materia. 


\section{Referencias}

Aicher, O. (1994). El mundo como proyecto. Barcelona, España: Gustavo Gili.

Alpers, S. (2001). La creación de Rubens. Madrid, España: Antonio Machado, Balsa de la Medusa.

Bal, M. (2016). Tiempos trastornados. Análisis, historias y políticas de la mirada. Madrid, España: Akal.

Baudrillard, J. (1984). Cultura y simulacro. Barcelona, España: Kairós.

Baudrillard, J. (1999). El sistema de los objetos. Ciudad de México, México: Siglo XXI Editores.

Berger, J. (2006). El sentido de la vista. Madrid, España: Alianza.

Betts, M. (2017). Crítica a la mediación cultural del diseño. Revista KEPES, 14 (16), 147-173.

Boehm, G. (2011). El giro pictorial. Una respuesta. Correspondencia entre Gottfried Boehm y W.J. Thomas Mitchell (II). En A. García Varas (Ed.), Filosofía de la imagen (pp. 71-86). Salamanca, España: Universidad de Salamanca.

Calvera, A. (2007) (Ed.). De lo bello de las cosas: materiales para una estética del diseño. Barcelona, España: Gustavo Gili.

Collingwood, R.G. (1960). Los principios del arte. Ciudad de México, México: Fondo de Cultura Económica.

Collingwood, R.G. (2016). El arte y la imaginación. Madrid, España: Casimiro.

Contreras, F.R. (2017). Estudio de los planteamientos teóricos y metodológicos de los estudios visuales. Arte, Individuo y Sociedad, 29 (3), 483-499. 
Croce, B. (1945). Breviario de estética. Buenos Aires, Argentina: Espasa-Calpe.

Dorfles, G. (1974). Las oscilaciones del gusto: el arte de hoy entre la tecnocracia y el consumismo. Barcelona, España: Lumen.

Flusser, V. (2002). Filosofía del diseño. Madrid, España: Síntesis.

Flusser, V. (2017). El universo de las imágenes técnicas. Elogio de la superficialidad. Buenos Aires, Argentina: Caja Negra.

Fried, M. (2000). Estética y orígenes de la pintura moderna. Madrid, España: Antonio Machado, Balsa de la Medusa.

Fritz Haug, W. (1987). Commodity aesthetics, ideology \& culture. New York, USA: International General.

Fritz Haug, W. (1989). Publicidad y consumo: crítica de la estética de mercancías. Ciudad de México, México: Fondo de Cultura Económica.

Glaser, M. (2017). Conversaciones con Peter Mayer. Barcelona, España: Gustavo Gili.

Greenberg, C. (2002). Arte y cultura. Barcelona, España: Paidós.

Groys, B. (2005). Sobre lo nuevo. Valencia, España: Pretextos.

Groys, B. (2016). Arte en flujo. Ensayos sobre la evanescencia del presente. Buenos Aires, Argentina: Caja Negra.

Hadjinicolaou, N. (1975). Historia del arte y lucha de clases. Madrid, España: Siglo XXI de España editores.

Harman, G. (2015). Hacia el realismo especulativo. Ensayos y conferencias. Buenos Aires, Argentina: Caja Negra.

Heidegger, M. (2012). Caminos del bosque. Madrid, España: Alianza Editorial. 
Heller, S. (2008). La anatomía del diseño: influencias e inspiraciones del diseño gráfico contemporáneo. Barcelona, España: Blume.

Huisman, D. (2002). La estética. Barcelona, España: Montesinos.

Infante del Rosal, F. (2018). La autonomía del diseño: diseño como categoría estética. Valencia, España: Universitat de València.

Julier, G. (2010). La cultura del diseño. Barcelona, España: Gustavo Gili.

Kant, I. (2004). Crítica de la razón pura. Madrid, España: Alfaguara.

Leborg, C. (2013). Gramática visual. Barcelona, España: Gustavo Gili.

Lipovetsky, G. (2004). El imperio de lo efímero: la moda y su destino en las sociedades modernas. Barcelona, España: Anagrama.

Marx, K. (2008). El Capital. Crítica de la economía política. El proceso de producción del capital I. Ciudad de México, México: Siglo XXI Editores.

Meggs, P.B. (2009). Historia del diseño gráfico. Barcelona, España: RM Verlag.

Morris, W. (2005). Escritos sobre arte, diseño y política. Sevilla, España: Doble J.

Moxey, K. (2015). El tiempo de lo visual. La imagen en la historia. Barcelona, España: Sans Soleil Ediciones.

Munari, B. (2005). El arte como oficio. Barcelona, España: Idea Books.

Pérez-Henao, H. (2014). El lugar de la estética en la vida diaria: historia del concepto de estética cotidiana. Revista KEPES, 10, 227-248.

Rosler, M. (2017). Clase cultural. Arte y gentrificación. Buenos Aires, Argentina: Caja Negra.

Simmel, G. (2013). Filosofía del paisaje. Madrid, España: Casimiro. 
Sparke, P. (2010). Diseño y cultura: una introducción: desde 1900 hasta la actualidad. Barcelona, España: Gustavo Gili.

Thomas, K. (2001). Diccionario del arte actual. Barcelona, España: Labor.

Wollen, P. (2006). El asalto de la nevera. Reflexiones sobre la cultura del siglo XX. Madrid, España: Akal.

Wollheim, R. (1972). El arte y sus objetos. Introducción a la estética. Barcelona, España: Seix Barral.

Como citar: Contreras, F.R. (2019). Estudio filosófico sobre la mirada estética en el diseño. Revista KEPES, 16 (19),11-38. DOI: 10.17151/kepes.2019.16.19.2 